\title{
Cerebral aneurysms - an audit
}

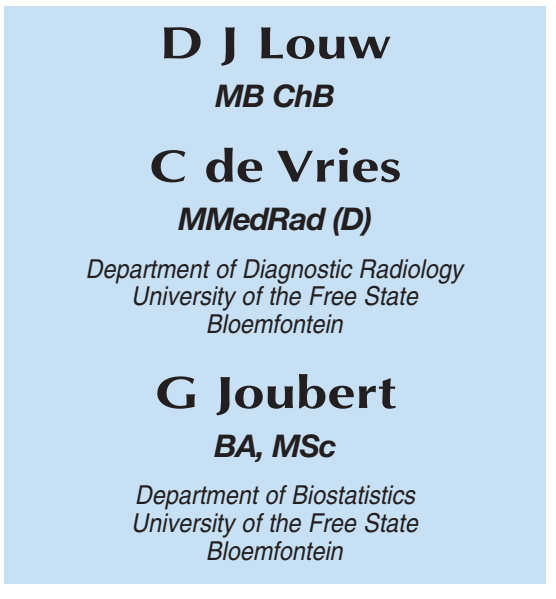

\section{Abstract}

We performed an audit to determine the profile of cerebral aneurysms at the Universitas Hospital Bloemfontein, the only government hospital with a vascular suite in the Free State and Northern Cape area. Two hundred and twenty-three government patients, diagnosed with cerebral aneurysms during the period 1 January 2000 to 31 December 2003, were included in the study. Of the 223 patients, $37.2 \%$ were male and $62.8 \%$ female. The patients' average age was 45.5 years (range $11-78$ years). Most patients $(61.4 \%)$ were older than 40 years. The average age for males and females was 41.4 and 46.3 years, respectively, with the females being significantly older (95\% CI: 1.7 - 8.2). Most patients had single aneurysms (65.5\%). More females (42.9\%) had multiple aneurysms compared with the males $(20.5 \%)$ ) $95 \%$ CI females males: 9.9 - 33.7\%). Of the patients 40 years and younger, $22.1 \%$ had multi- ple aneurysms compared with $42.3 \%$ of the patients older than 40 years (95\% CI: 7.8 - 31.7\%). In our audit the females (when compared with the males) had a clear preponderance for cerebral aneurysms, were significantly older, and had a significant increase in multiplicity with an increase in age.

\section{Introduction}

The main cause of subarachnoid haemorrhage (SAH) is rupture of cerebral aneurysms. ${ }^{1} \mathrm{SAH}$ is a very serious disease associated with high mortality and morbidity. ${ }^{1}$ It is still an open question whether populationwide screening for unruptured cerebral aneurysms is indicated, ${ }^{2}$ while cerebral angiography remains the diagnostic gold standard. ${ }^{3,4}$

There have been numerous studies of the incidence of cerebral aneurysms. According to the WHO MONICA (Multinational Monitoring of Trends and Determinants in Cardiovascular Disease) Stroke Study no consistent pattern was observed in SAH attack rates in different populations. ${ }^{5}$ We performed an audit to determine the profile of cerebral aneurysms at Universitas Hospital, Bloemfontein.

\section{Methods}

Universitas Hospital in Bloemfontein is the only tertiary hospital in the Free State and Northern Cape and also the only government hospital with a vascular suite in this area. All government patients with a suspected SAH are therefore sent to this unit for angiographic assessment. During the period 1 January 2000 to 31 December 2003, 223 patients were diagnosed with cerebral aneurysms. The angiogram reports of these patients were used for data collection. Reports of repeat and follow-up aneurysms were excluded.

Angiography was perfomed using a Siemens angioscope unit. Four vessel studies were performed in most cases using the following projections: AP, left anterior oblique (LAO) $20^{\circ}$, right anterior oblique (RAO) $20^{\circ}$ and lateral for the carotid arteries, and Townes and lateral projections for the vertebral arteries.

\section{Results}

Of the 223 patients, $83(37.2 \%)$ were male and $140(62.8 \%)$ were female. The patients' average age was 45.5 years (range $11-78$ years), with a peak (48.9\%) between the ages of 36 and 50 years (Fig. 1). The majority of patients $(61.4 \%)$ were older than 40 years. The average age for males was 41.4 years and 46.3 years for females, with the females being significantly older (95\% CI: 1.7 - 8.2). The average age for males with single aneurysms was 40.5 years, and for multiple aneurysms, 41.1 years. The average age for females with single aneurysms was 43.1 years, and for multiple aneurysms, 50.5 years.

Seventy-seven patients $(34.5 \%)$ had multiple aneurysms while 146 patients $(65.5 \%)$ had single aneurysms. In the female group, 60 (42.9\%) had multiple aneurysms compared with $17(20.5 \%)$ of the males (95\% CI: females - males 9.9 $33.7 \%)$. Of the patients 40 years and younger, $22.1 \%$ had multiple 


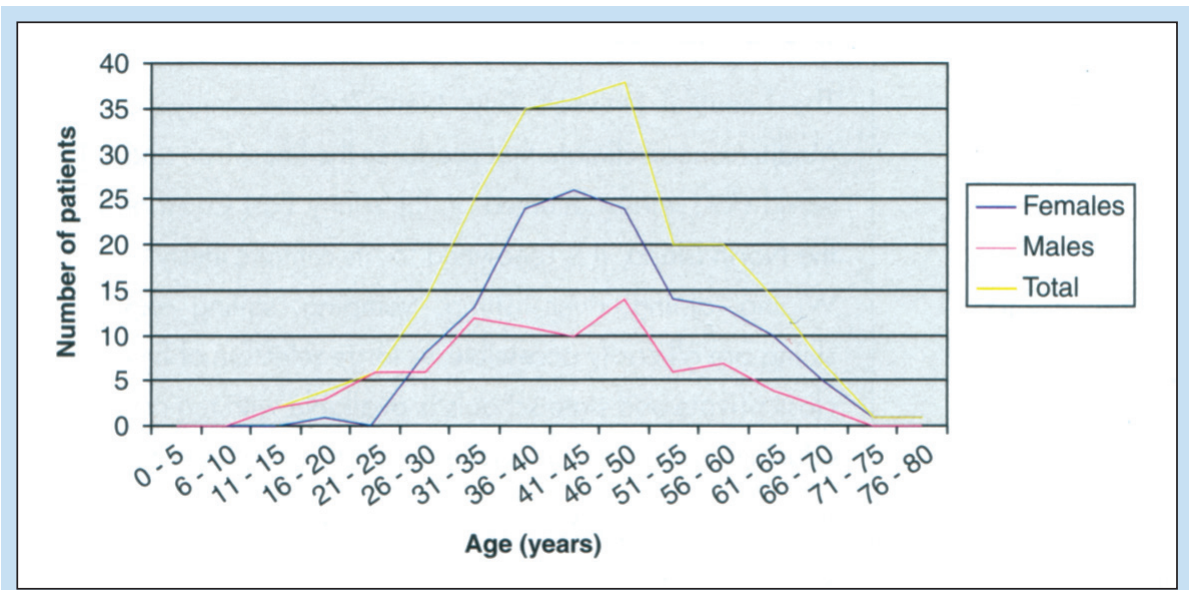

Fig. 1. Age distribution of the patients $(\mathrm{N}=223)$.

aneurysms compared with $42.3 \%$ of the patients older than 40 years ( $95 \%$ CI: 7.8 - 31.7\%).

The sites of the aneurysms are given in Fig. 2. In the patients with multiple aneurysms, each site was counted separately. The internal carotid artery and posterior communicating artery accounted for the most sites, viz. 76 (22.8\%) and 75 (22.5\%), respectively.

To determine seasonal variation, the year was divided into 3-month periods, starting with 1 September, indicating spring. The number of single aneurysms increased during winter (1 June - 31 August), but this was,

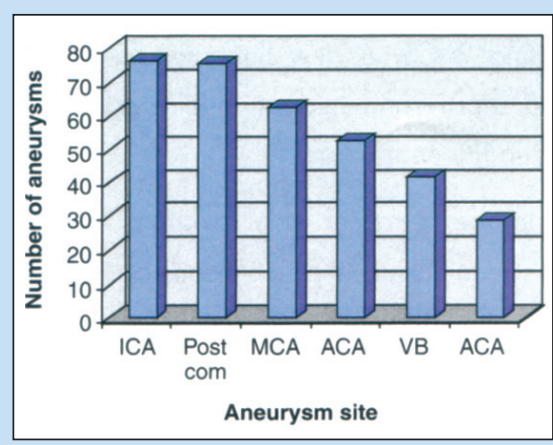

Fig. 2. Site of aneurysms $(\mathrm{N}=334)(I C A=$ internal carotid artery; Post com = posterior communicating artery; $M C A=$ middle cerebral artery; $A C A=$ anterior cerebral artery; $V B=$ vertebrobasilar system). however, not statistically significant (chi-square $p$-value 0.5370).

\section{Discussion}

Previous data suggest that cerebral aneurysms occur more frequently with increasing age, ${ }^{6}$ peaking in the fourth to fifth decade, and rarely occurring after 75 years. ${ }^{7.8}$ This is also reflected in our audit, with most patients (61.4\%) older than 40 years.

According to some authors cerebral aneurysm is a disease with a female preponderance, with the mean age for women older than for men..$^{3,9-11}$ In the WHO MONICA study no consistent pattern was observed in the sex ratio of attack rates in different populations, with men having a higher incidence in Finland and Russia. Women had a higher incidence in Poland, Northern Sweden and Denmark. The incidence was the same for East Germany, China, Yugoslavia and Italy. ${ }^{5}$ In our audit the females had a clear preponderance accounting for $62.8 \%$ of the study population, and were significantly older (95\% CI: 1.7 - 8.2). The femaleto-male ratio also increased after the fourth decade, as found by Kongable and co-workers. ${ }^{10}$ The ratio increased to $1: 2.1$ in the fifth decade compared with 1:1.55 in the third decade. The overall ratio was 1:1.7.

The incidence of multiple cerebral aneurysms has been variably assessed at between $5 \%$ and $33 \%$. $^{3,612-17}$ In this study, $34.5 \%$ of the patients had multiple cerebral aneurysms (ratio 1:2). Of the patients older than 40 years, $42.3 \%$ had multiple aneurysms. Previous data also suggest that multiplicity increases with age. ${ }^{6}$ Females had a significant increased incidence in our study (95\% CI: 9.9 - 33.7\%). There is a higher mortality associated in patients with multiple lesions. ${ }^{13,18}$

An apparent seasonal variation was found in this study, with an increase in single aneurysms during winter. This was, however, not statistically significant and needs to be compared with other South African results.

We also wanted to audit the size of the aneurysms, the shape of the neck and aneurysms, as well as treatment. Unfortunately these data were not available consistently enough on the reports to audit. This underlines the need to use a standardised format of reporting.

\section{References}

1. Pakarinen S. Incidence, aetiology, and prognosis of primary subarachnoid haemorrhage. A study based on 589 cases diagnosed in a defined urban population during a defined period. Acta Neurol Scand 1967; 43: Suppl 29, 1-28.

2. Wardlaw JM, White PM. The detection and management of unruptured intracranial aneurysms. Brain 2000; 123: 205-221.

3. van Gijn J, Rinkel GJ. Subarachnoid haemorrhage: diagnosis, causes and management (Review) Brain 2001; 124: 249-278.

4. Mayberg MR, Batjer HH, Dacey $\mathrm{R}$, et al. Guidelines for the management of aneurysmal subarachnoid hemorrhage. A statement for healthcare professionals from a special writing group of the Stroke Council, American Heart Association. Stroke 1994; 25: 2315-2328.

5. Ingall T, Asplund K, Mahonen M, Bonita R. A multinational comparison of subarachnoid hemorrhage epidemiology in the WHO MONICA stroke study. Stroke 2000; 31: 1054-1061. 
6. Wilson FM, Jaspan T, Holland IM. Multiple cerebral aneurysms - a reappraisal. Neuroradiology 1989; 31: 232-236.

7. Clare CE, Barrow DL. Infectious intracranial aneurysms. Neurosurg Clin N Am 1992; 3: 551-566.

8. McCormick WF, Acosta-Rua GJ. The size of intracranial saccular aneurysms. An autopsy study. J Neurosurg 1970; 33: 422-427.

9. Bonita R, Thomson S. Subarachnoid hemorrhage: epidemiology, diagnosis, management, and outcome. Stroke 1985; 16: 591-594.

10. Kongable GL, Lanzino G, Germanson TP, et al. Gender-related differences in aneurysmal subarachnoid hemorrhage. J Neurosurg 1996; 84: 43-48.

11. Ogungbo B, Gregson BA, Blackburn A, Mendelow AD; Newcastle Subarachnoid Study Group. Trends over time in the management of subarachnoid haemorrhage in Newcastle: review of 1609 patients. $\mathrm{Br} \mathrm{J}$ Neurosurg 2001; 15: 388-395.

12. Hamby WB. Multiple intracranial aneurysms. Aspects of treatment. $J$ Neurosurg 1959; 16: 558-563.

13. McKissock W, Richardson A, Walsh L, Owen E. Multiple intracranial aneurysms. Lancet 1964; 15: 623-626.

14. Heiskanen O. Multiple intracranial arterial aneurysms. Acta Neurol Scand 1966; 41: 356-362.

15. King G, Slade HW, Campoy F. Bilateral intracranial aneurysms. AMA Arch Neurol Psychiatry 1954; 71: 326-336.

16. Ostergaard JR, Hog E. Incidence of multiple intracranial aneurysms. Influence of arterial hypertension and gender. J Neurosurg 1985; 63: 49-55.

17. Sengupta RP, McAllister VL. Subarachnoid Haemorrhage. New York: Springer-Verlag, 1986.

18. Paterson A, Bond MR. Treatment of multiple intracranial arterial aneurysms. Lancet 1973; 1: 1302-1304. 